\title{
Ctip2 Controls the Differentiation of Medium Spiny Neurons and the Establishment of the Cellular Architecture of the Striatum
}

\author{
Paola Arlotta, ${ }^{1 *}$ Bradley J. Molyneaux, ${ }^{1 *}$ Denis Jabaudon, ${ }^{1}$ Yutaka Yoshida, ${ }^{2}$ and Jeffrey D. Macklis ${ }^{1}$ \\ ${ }^{1}$ Massachusetts General Hospital-Harvard Medical School Center for Nervous System Repair, Nayef Al-Rodhan Laboratories, Departments of Neurosurgery \\ and Neurology, Program in Neuroscience, and Harvard Stem Cell Institute, Harvard Medical School, Massachusetts General Hospital, Boston, \\ Massachusetts 02114, and 2Department of Biochemistry and Molecular Biophysics, Center for Neurobiology and Behavior, Howard Hughes Medical \\ Institute, Columbia University, New York, New York 10032
}

Striatal medium spiny neurons (MSN) are critically involved in motor control, and their degeneration is a principal component of Huntington's disease. We find that the transcription factor Ctip2 (also known as Bcl11b) is central to MSN differentiation and striatal development. Within the striatum, it is expressed by all MSN, although it is excluded from essentially all striatal interneurons. In the absence of Ctip2, MSN do not fully differentiate, as demonstrated by dramatically reduced expression of a large number of MSN markers, including DARPP-32, FOXP1, Chrm4, Reelin, MOR1 ( $\mu$-opioid receptor 1), glutamate receptor 1, and Plexin-D1. Furthermore, MSN fail to aggregate into patches, resulting in severely disrupted patch-matrix organization within the striatum. Finally, heterotopic cellular aggregates invade the Ctip2 $2^{-/-}$striatum, suggesting a failure by MSN to repel these cells in the absence of Ctip2. This is associated with abnormal dopaminergic innervation of the mutant striatum and dramatic changes in gene expression, including dysregulation of molecules involved in cellular repulsion. Together, these data indicate that Ctip2 is a critical regulator of MSN differentiation, striatal patch development, and the establishment of the cellular architecture of the striatum.

Key words: Ctip2; striatum; medium spiny neurons; striasomes; striatal patches; secretagogin

\section{Introduction}

The striatum plays a central role in the coordination of movement, emotions, and cognition (Gerfen, 1992; Jain et al., 2001; Graybiel, 2005). GABAergic medium-sized spiny neurons (MSN), the output projection neurons of the striatum, account for the vast majority ( $\sim 90-95 \%)$ of all striatal neurons (Kemp and Powell, 1971; Gerfen, 1992). The remaining 5-10\% of striatal neurons are interneurons that can be subdivided into different functional classes based on neurotransmitter/neuropeptide profiles, and distinct morphological and electrophysiological properties (Kawaguchi, 1993; Kawaguchi et al., 1995; Tepper and Bolam, 2004). Clinically, MSN are an important population of projection neurons, because their degeneration is a critical component of Huntington's disease; they are also an essential element

\footnotetext{
Received April 13, 2006; revised 0ct. 7, 2007; accepted Dec. 1, 2007.

This work was partially supported by national Institutes of Health Grants NS45523 and NS49553, and the Harvarc Stem Cell Institute (J.D.M). P.A. was supported by a Claflin Distinguished Scholar Award and the Harvard Stem Cell Institute. B.J.M. was supported by the Harvard Medical Scientist Training Program and the United Sydney Association. We thank A. Eswar, K. MacQuarrie, A. Meleski, and K. Quinn for technical assistance; Drs. M. Leid, A. Banham, D. Simon, L. Wagner, and A. Mallamaci for generously sharing antibodies and probes; and Drs. G. Fishell, P. Bhide, J. Menezes, and members of the Macklis lab for suggestions and critical reading of this manuscript.

*P.A. and B.J.M. contributed equally to this work.

Correspondence should be addressed to Jeffrey D. Macklis at the above address. E-mail: jeffrey_macklis@hms.harvard.edu.

DOI:10.1523/JNEUROSCI.2986-07.2008

Copyright $\odot 2008$ Society for Neuroscience $\quad$ 0270-6474/08/280622-11\$15.00/0
}

of the circuitry that degenerates in Parkinson's disease (Albin et al., 1989).

Transplantation and birth-dating studies have shown that MSN are born from Dlx1/2-positive progenitors located in the germinal zone of the developing lateral ganglionic eminence (LGE) (Deacon et al., 1994; Olsson et al., 1995, 1997; Wichterle et al., 2001). After migrating radially into the developing striatum, MSN segregate into two principal compartments: the patches (also known as striasomes) and the matrix that surrounds them (for review, see Gerfen, 1992). The first MSN to migrate into the developing striatum aggregate into the patches, whereas latergenerated neurons form the matrix (van der Kooy and Fishell, 1987; Krushel et al., 1989, 1995; Song and Harlan, 1994). Striatal patches develop concomitantly with the arrival of dopaminergic afferents from the substantia nigra, which reach the striatum at embryonic day 14 (E14) and cluster at the patches by E19 (Moon Edley and Herkenham, 1984).

Several transcription factors have been shown to regulate the development of patch and/or matrix neurons by acting on the progenitors of MSN. For example, lack of $D l x 1 / 2$ causes arrested migration of matrix neurons within the subventricular zone (SVZ) (Anderson et al., 1997b), and Mash1 null-mutant mice exhibit a loss of neuronal progenitors, resulting in a reduction of defined neuronal populations in the basal ganglia (Casarosa et al., 1999). Other studies have looked at the effect of neurotrophin signaling on MSN development; these have found that TrkB re- 
ceptor signaling via its ligand BDNF is implicated in both patch and matrix MSN maturation in vitro (Ivkovic and Ehrlich, 1999). In contrast, less is known about the transcription factor codes that regulate MSN differentiation and patch-matrix development after the progenitor stage.

We demonstrated previously that the transcription factor COUP TF1-interacting protein 2 (CTIP2) plays critical roles during axonal extension and pathfinding by subcerebral projection neurons of the cerebral cortex (Arlotta et al., 2005). Here, we report that within the striatum Ctip2 is uniquely expressed by MSN, specifically labeling this critical neuronal population from early postmitotic stages. Loss of Ctip 2 function results in a failure of MSN differentiation, disruption of the patch-matrix organization of MSN, and distinct changes in the expression of multiple genes, including novel molecular identifiers of the patch compartment. The defect in patch aggregation also results in abnormal dopaminergic innervation of the striatum. Finally, there is an alteration in the expression of molecules involved in cellular repulsion and the appearance of heterotopias within the mutant striatum, strongly suggesting that the loss of Ctip2 disrupts normal mechanisms of cellular repulsion during development.

\section{Materials and Methods}

Ctip2 ${ }^{-1-}, \mathrm{Chrm} 4^{\mathrm{GFP}}$, and Plexin-D1 ${ }^{-1-}$ mice. Ctip $2^{-/-}$mice, generated by Wakabayashi et al. (2003), have a neomycin resistance gene inserted into exon 1 of the Ctip2 gene, blocking CTIP2 expression. Ctip2 mutant mice were maintained on a BALB/c background. Chrm $4^{\text {GFP }}$ transgenic mice, which express enhanced green fluorescent protein (EGFP) under the control of the m4human muscarinic receptor (chrm4) promoter, were generated by the GENSAT Project using a bacterial artificial chromosome containing the Chrm 4 locus on a Swiss Webster background and were backcrossed to the BALB/c background for two generations before crossing to Ctip2 heterozygotes. (Gong et al., 2003; Lobo et al., 2006). Plexin-D1 $1^{-1-}$ mice, generated by Yoshida and colleagues and maintained in the C57BL/6 background (Gu et al., 2005), have a neomycin resistance gene inserted into exon 1 of the Plexin-D1 gene, blocking Plexin-D1 expression. For all embryonic experiments, the day of vaginal plug was designated E0.5. The day of birth was designated postnatal day 0 (P0). All mouse studies were approved by the Massachusetts General Hospital Institutional Animal Care and Use Committee and performed in accordance with institutional and federal guidelines.

Immunocytochemistry and in situ hybridization. Brains were fixed and stained using standard methods (Fricker-Gates et al., 2002). Briefly, brains were fixed by transcardial perfusion with PBS-heparin $(10 \mathrm{U} / \mathrm{ml})$ followed by $4 \%$ paraformaldehyde, and postfixed overnight at $4^{\circ} \mathrm{C}$ in $4 \%$ paraformaldehyde. Brains were sectioned coronally at $40 \mu \mathrm{m}$ on a vibrating microtome (Leica, Nussloch, Germany). Sections were blocked in $0.3 \%$ BSA (Sigma, St. Louis, MO), $8 \%$ goat or donkey serum, and $0.3 \%$ Triton X-100 (Sigma) for $1 \mathrm{~h}$ at room temperature, before incubation in primary antibody. Primary antibodies and dilutions used were rat antiCTIP2 (1:500; a gift from Mark Leid, Oregon State University, Corvallis, OR) (Senawong et al., 2003); rabbit anti-dopamine and cAMP-regulated phosphoprotein $32 \mathrm{kDa}$ (DARPP-32), 1:250 (Millipore, Temecula, CA); mouse anti-FOXP1 (JC12; 1:10; a gift from Alison Banham, University of Oxford, Oxford, UK) (Banham et al., 2001); rabbit anti-FOXP1 (1:500, a gift from Daniel Simon, Harvard Medical School, Boston, MA) (Shi et al., 2004); goat anti-ChAT (1:100; Millipore); rabbit anti-somatostatin (1: 100; Millipore); mouse anti-parvalbumin (1:2000; Millipore); antiMAP2 (1:500; Sigma); anti-cleaved caspase 3 (1:750; NEB, Ipswich, MA); rat anti-BrdU (1:400; Accurate, Westbury, NY); rabbit anti-MOR1 (1: 1000; Abcam, Cambridge, MA); rabbit anti-Secretagogin (1:3000; a gift from Ludwig Wagner, Medical University of Vienna, Vienna, Austria) (Gartner et al., 2001); mouse anti-Reelin (1:400; Millipore); rabbit antiGluR1 (1:30; Millipore); mouse anti-TH (1:500; Millipore). Appropriate secondary antibodies were from the Invitrogen (Carlsbad, CA) Alexa series. Laser confocal analysis was performed using a Bio-Rad (Hercules,
CA) Radiance 2100 confocal system attached to a Nikon (Tokyo, Japan) E800 microscope.

BrdU labeling. Timed pregnant females received a single intraperitoneal injection of bromodeoxyuridine (BrdU) $(100 \mathrm{mg} / \mathrm{kg})$ at E12.5. Embryos were collected at E19.5 or at P0. Brains were removed, fixed overnight at $4^{\circ} \mathrm{C}$ with $4 \%$ paraformaldehyde, and sectioned coronally at 40 $\mu \mathrm{m}$ thickness using a vibrating microtome (Leica). BrdU immunocytochemistry was performed as described previously (Magavi et al., 2000). For the detection of BrdU-positive nuclei, matching sections from three Ctip $2^{-1-}$ and three wild-type littermates (every sixth section) were imaged, and two independent investigators, blinded to genotype, scored each section for the presence of BrdU-positive nuclei clustered in patches. There was high interobserver reliability, documenting a reduction in aggregation of BrdU-labeled MSN into patches within the mutant striatum. For the quantification of BrdU-positive cells born at E12.5, five matched sections were counterstained with FOXP1 (a marker of MSN) to define the dorsoventral and mediolateral limits of the striatum, including the subcallosal streak. Two independent investigators, blinded to genotype, counted the total number of first-generation BrdU-positive nuclei across the entire striatum and subcallosal streak in three Ctip $2^{-/-}$and three wild-type littermates.

TUNEL and Fluoro-Jade B staining. Terminal deoxynucleotidyl transferase-mediated biotinylated UTP nick end labeling (TUNEL) staining was performed using the DeadEnd Fluorometric TUNEL system (Promega, Madison, WI), following the instructions of the manufacturer. Fluoro-Jade B staining was performed according to Schmued and Hopkins (2000).

Affymetrix microarrays. Matched regions of striatum from wild-type and Ctip $2^{-1-}$ mice were obtained via $500-\mu \mathrm{m}$-diameter punch biopsies performed in the center of the developing striatum in acutely sectioned $300 \mu \mathrm{m}$ coronal slices of the brain at P0. Sections were matched rostrocaudally between wild-type and null mutant tissue, and fiduciary landmarks were used to assure reproducible microdissection of comparable regions. RNA was extracted using the StrataPrep Total RNA Mini Kit (Stratagene, La Jolla, CA), and RNA quality was assayed using a bioanalyzer (Agilent Technologies, Paola Alto, CA). To ensure reproducibility and biological significance, microarrays were performed with RNA samples from three independent wild-type and four Ctip $2^{-1-}$ mice (biological replicates). Microarray data were normalized using two independent methods: the RMA function within Bioconductor (Irizarry et al., 2003) and the "error model" method within Rosetta Resolver (version 5.0; Rosetta Biosoftware, Seattle, WA). Statistical significance of gene expression differences between wild-type and knock-out was determined using statistical analysis of microarrays (SAM) (Tusher et al., 2001). Using a SAM D-score cutoff of $>2$ or less than -2 , we selected the 153 most significant genes and further analyzed them to identify a smaller set of genes of potentially high biological relevance. All microarray data have been deposited in the Gene Expression Omnibus database at National Center for Biotechnology Information (accession number GSE9330).

In situ hybridization. In situ hybridization was performed using reported methods (Berger and Hediger, 2001). The probe for Plexin-D1 was as previously reported (Molyneaux et al., 2005), and the Nrp1 probe was a gift from Antonello Mallamaci (S.I.S.S.A., Trieste, Italy). Template cDNA were amplified by RT-PCR using the primers listed in supplemental Table 1 (available at www.jneurosci.org as supplemental material) for the following genes: Basonuclin2, Ebf1, Fidgetin, Kcnip2, Meis2, Nectin-3, Neto1, Neurotensin, Ngef, Nolz-1, Pcp4l1, Semaphorin 3A, Semaphorin $3 C$, Semaphorin $3 E$, Semaphorin $3 F$, and Unc5d.

\section{Results \\ Striatal CTIP2 expression is restricted to medium spiny neurons}

CTIP2 is a transcription factor reported previously to be expressed in specific regions of the CNS, including the neocortex, the hippocampus, the olfactory bulb, and the striatum, from early embryonic stages of development (Leid et al., 2004; Arlotta et al., 2005). Within the striatum, CTIP2 is expressed in the vast majority of cells, suggesting that it might be expressed in MSN, which 

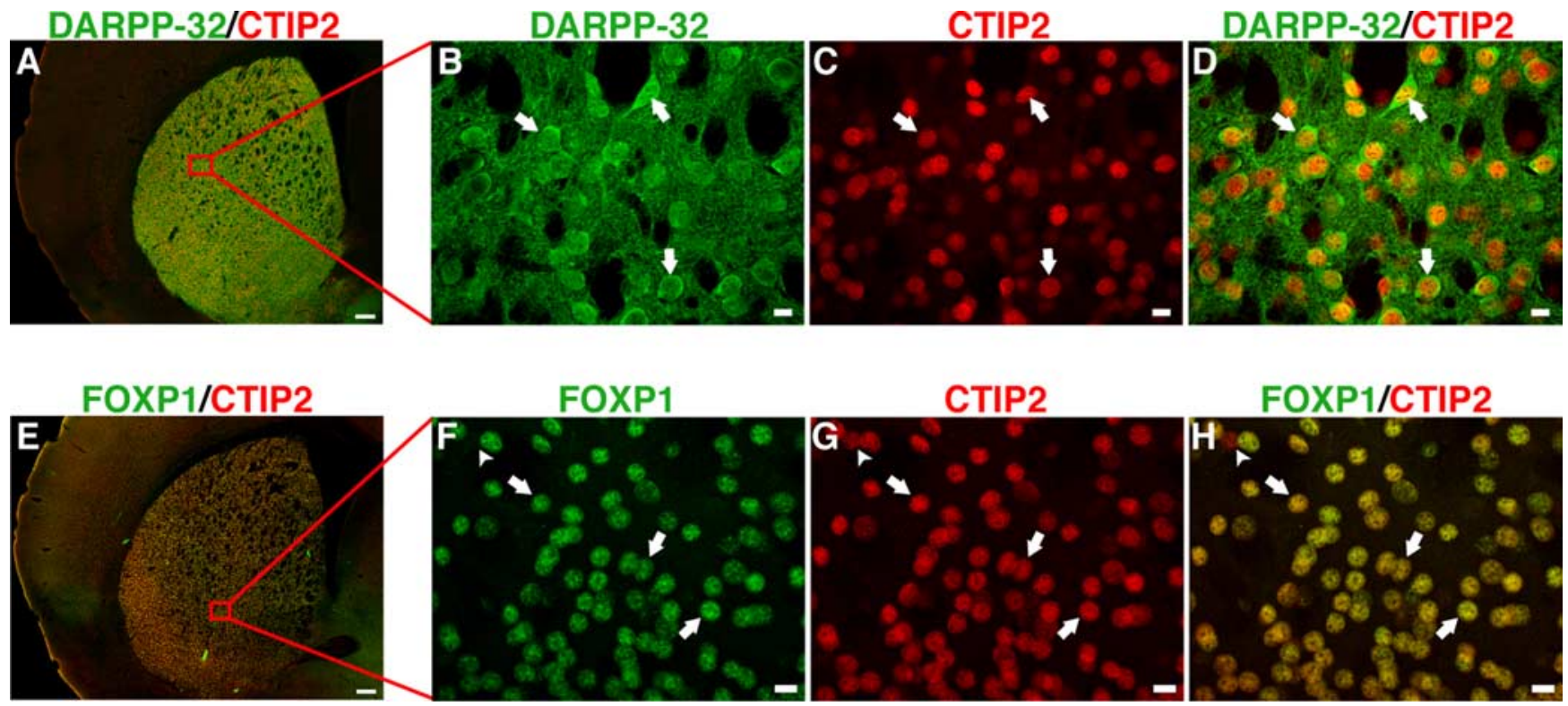

Figure 1. CTIP2 is specifically expressed in medium spiny neurons. $A-D$, CTIP2 expression in MSN labeled with DARPP-32. $A$, Coronal section of adult striatum, showing colocalization of CTIP2 (red) with DARPP-32 labeled MSN (green). $\boldsymbol{B}, \boldsymbol{C}$, High-magnification image of DARPP-32 expression ( $\boldsymbol{B})$ and CTIP2-labeled nuclei $(\boldsymbol{C})$ in the boxed area in $\boldsymbol{A}$. $\boldsymbol{D}$, Merged image of $\boldsymbol{B}$ and $\boldsymbol{C}$, showing that all DARPP-32 labeled MSN express CTIP2. E-H, CTIP2 expression in MSN labeled with FOXP1. E, Coronal section of adult striatum, showing colocalization of (TIP2 (red) with F0XP1 labeled MSN (green). $\boldsymbol{F}, \boldsymbol{G}$, High-magnification image of FOXP1-labeled MSN $(\boldsymbol{F})$ and $(\mathrm{TIP2}$-labeled nuclei $(\boldsymbol{G})$ in the boxed area in $\boldsymbol{E}$. $\boldsymbol{H}$, Merged image of $\boldsymbol{F}$ and $\boldsymbol{G}$, showing that all FOXP1-labeled MSN express CTIP2. Fewer than $1 \%$ of (TIP2-labeled cells are F0XP1 negative (arrowhead). Arrows indicate examples of colocalization. Scale bars: $\boldsymbol{A}, \boldsymbol{E}, 200 \mu \mathrm{m} ; \boldsymbol{B}-\boldsymbol{D}, \boldsymbol{F}-\boldsymbol{H}, 10 \mu \mathrm{m}$.

comprise $\sim 95 \%$ of striatal neurons (Kemp and Powell, 1971; Gerfen, 1992). To investigate this, we performed immunocytochemistry in the adult striatum for CTIP2, combined with colocalization with two different cell-type-specific markers for MSN: DARPP-32 and forkhead box P1 (FOXP1). DARPP-32 is expressed in $\sim 95 \%$ of medium spiny neurons and is not expressed by other cell types within the striatum (Ouimet et al., 1984; Ouimet and Greengard, 1990; Anderson and Reiner, 1991; Ouimet et al., 1998). We find that all DARPP-32 positive cells express CTIP2 in the adult striatum ( $n=2239$ of 2239 cells) (Fig. $1 A-D)$, supporting the conclusion that all MSN express CTIP2. Colabeling with FOXP1, a transcription factor expressed by MSN, but not striatal interneurons (Tamura et al., 2004), confirmed this conclusion by showing that all FOXP1-positive cells express CTIP2 ( $n=3398$ of 3398 cells) (Fig. $1 E-H$ ).

We next investigated whether CTIP2 expression is restricted to only MSN and excluded from other neuronal populations within the striatum. Using immunocytochemistry for the four principal types of striatal interneurons (Kawaguchi et al., 1995; Tepper and Bolam, 2004), we find that no somatostatinexpressing ( $n=0$ of 349), ChAT-expressing ( $n=0$ of 577 ), or calretinin-expressing ( $n=0$ of 260) neurons express CTIP2, and only 1 of 567 parvalbumin-positive cells examined $(<0.02 \%)$ exhibited colocalization with CTIP2 (Fig. 2). These data indicate that CTIP2 is uniquely expressed by MSN in the striatum, providing a specific marker of medium spiny neurons and suggesting that CTIP2 might play a role in MSN development.

During development, MSN are born in the lateral ganglionic eminence between E12 and P2 in rat (and corresponding developmental stages in mice) and then migrate radially away from the germinal zone into the developing striatum (Marchand and Lajoie, 1986; van der Kooy and Fishell, 1987). To define when during development MSN begin expressing CTIP2, we performed a developmental analysis of CTIP2 expression and colocalization with early neuronal and progenitor markers. In the LGE, CTIP2 is first detected at E12.5 (Arlotta et al., 2005) and continues to be strongly expressed throughout MSN neurogenesis from E13.5 into adulthood (Fig. $3 A-C$ ). Within the LGE, CTIP2 is not expressed in the ventricular or subventricular zones (Fig. $3 A$ ). Rather, at E13.5 and E17.5, it is expressed in the mantle zone of the developing striatum (Fig. 3A,B), suggesting that CTIP2 is first expressed in early postmitotic MSN and not in MSN progenitors. In agreement with these findings, CTIP2 expression colocalizes with immature doublecortin (Dcx)-positive migratory neurons at E13.5 (Fig. 3D-G) and is excluded from dividing progenitors in the VZ/SVZ, as identified by both phosphorylated histone 3 (PH3) and BrdU (Fig. $3 H-K, L-O$, respectively). CTIP2 expression levels increase in MSN as they migrate radially into the striatum (Fig. 3B), and this expression is maintained at high levels into adulthood (Fig. 3C).

Absence of CTIP2 impairs the spatial organization of medium spiny neurons into striatal patches

To investigate whether CTIP2 plays a functional role in medium spiny neuron development, we examined the striatum of Ctip $2^{-/-}$mice. Because Ctip2 $2^{-/-}$mice die within the first $24 \mathrm{~h}$ after birth (Wakabayashi et al., 2003; Arlotta et al., 2005), we examined the mutant striatum at P0, when the bulk of MSN neurogenesis is complete and MSN have migrated into the striatum. We previously found that the Ctip $2^{-1-}$ striatum is highly disorganized by Nissl staining (Arlotta et al., 2005), with a portion of the observed changes in striatal morphology and disorganization caused by the lateral shift and lack of fasciculation of axons of the internal capsule that perforate the striatum (Arlotta et al., 2005). In the neocortex, CTIP2 is expressed at high levels within corticospinal motor neurons and other subcerebral projection neurons of layer V and at low levels within layer VI corticothalamic projection neurons, all of which project through the internal capsule (Arlotta et al., 2005). It is unclear whether the axonal abnormalities that we previously reported in the internal capsule relate solely to the function of CTIP2 in cortical projec- 
Somatostatin

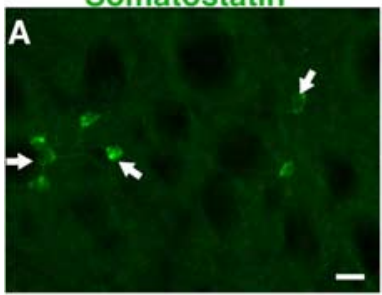

ChAT

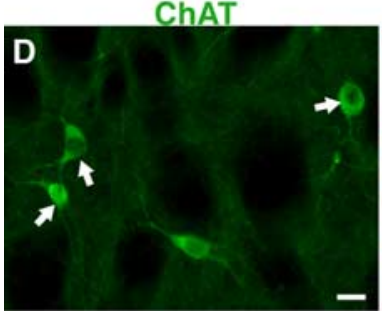

Calretinin

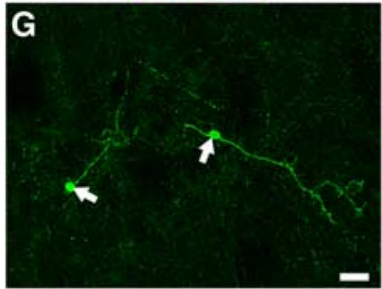

Parvalbumin

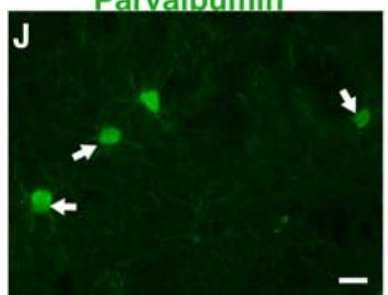

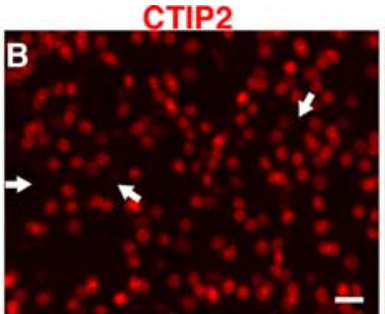

CTIP2

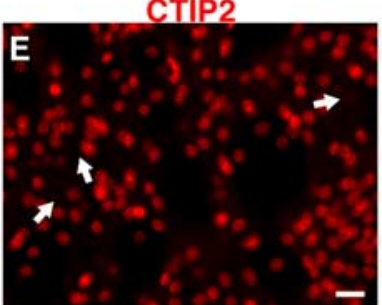

CTIP2

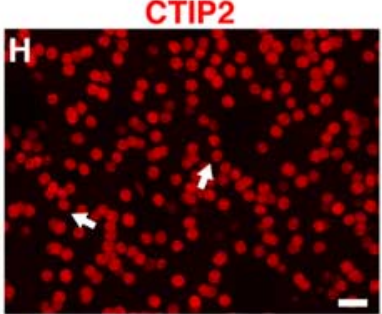

CTIP2

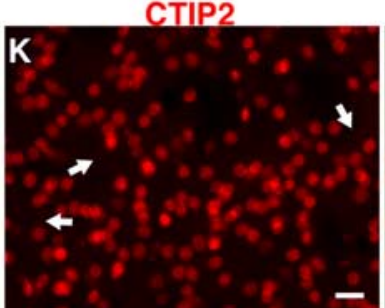

Somatostatin/CTIP2

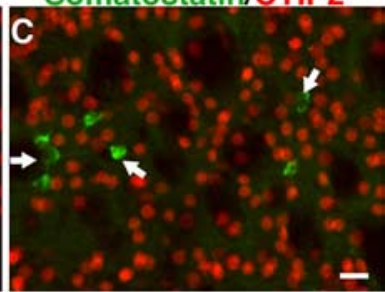

ChAT/CTIP2

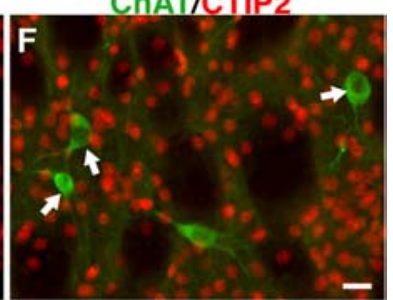

Calretinin/CTIP2

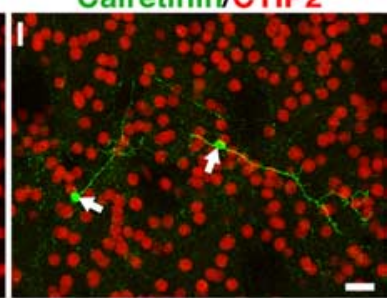

Parvalbumin/CTIP2

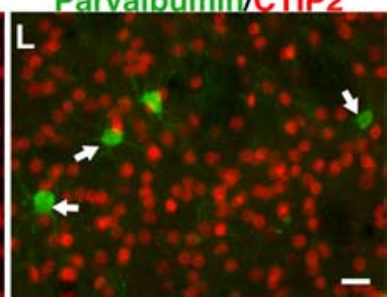

Figure 2. CTIP2 is not expressed in striatal interneurons. $\boldsymbol{A}, \boldsymbol{B}$, Somatostatin expression $(\boldsymbol{A})$ and CTIP2-labeled nuclei $(\boldsymbol{B})$ in the same area as $\boldsymbol{A}$. $\boldsymbol{C}$, Merged image of $\boldsymbol{A}$ and $\boldsymbol{B}$ showing that no somatostatin-expressing interneurons express CTIP2. D, $\boldsymbol{E}$, ChAT expression $(\boldsymbol{D})$ and $($ TIP2-labeled nuclei $(\boldsymbol{E})$ in the same area as $\boldsymbol{D}$. $\boldsymbol{F}$, Merged image of $\boldsymbol{D}$ and $\boldsymbol{E}$, showing that no ChAT-expressing interneurons express CTIP2. $\mathbf{G}, \boldsymbol{H}$, Calretinin expression ( $\boldsymbol{G}$ ) and CTIP2-labeled nuclei $(\boldsymbol{H})$ in the same area as $\boldsymbol{G}$. $\boldsymbol{I}$, Merged image of $\boldsymbol{G}$ and $\boldsymbol{H}$ showing that no Calretinin-expressing interneurons express (TIP2. $\boldsymbol{J}, \boldsymbol{K}$, Parvalbumin expression $(\boldsymbol{J})$ and (TIP2-labeled nuclei $(\boldsymbol{K})$ in the same area as $\boldsymbol{J}$. $\boldsymbol{L}$, Merged image of $\boldsymbol{J}$ and $\boldsymbol{K}$ showing that no parvalbumin-expressing interneurons express CTIP2. Arrows indicate examples of cells that do not express CTIP2. Scale bars, $20 \mu \mathrm{m}$.

tion neurons, to CTIP2 function in the striatum, or to a combination of the two.

Here, using Meis2 (Toresson et al., 2000a) and Nolz-1 (Chang et al., 2004) to label immature MSN within the developing LGE at E14.5 (supplemental Fig. 1 $A-D$, available at www.jneurosci.org as supplemental material), and FOXP1 to label MSN within the mantle zone of the striatum at E15.5 and at P0 (Fig. 4A, B, supplemental Fig. $1 E, F$, available at www.jneurosci.org as supplemental material), we find that loss of Ctip2 does not affect MSN birth and migration into the striatum. However, the differentiation of these neurons is impaired, as reflected by a decrease in FOXP1 expression as early as E15.5 and a disorganization in striatal compartments. Moreover, Chrm4, a marker of the striatonigral subset of MSN (Ince et al., 1997), is virtually absent from the striatum of the null-mutant at $\mathrm{P} 0$, as measured by the absence of GFP reporter gene expression from the Chrm4 locus in transgenic mice (Fig. 4C,D). These data indicate that in the absence of Ctip2 MSN are specified from progenitors and migrate into the mantle zone, but differentiate abnormally.

To determine whether lack of Ctip2 function is associated with abnormal organization of different striatal cellular compartments, we labeled P0 striatum from Ctip $2^{-1-}$ and wild-type littermates for DARPP-32, Reelin, $\mu$-opioid receptor 1 (MOR1), glutamate receptor 1 (GluR1), and microtubule-associated protein 2 (MAP2). Although patch-matrix segregation is not yet complete at $\mathrm{P} 0$, developing patches can be detected by these markers just before birth (Moon Edley and Herkenham, 1984; Foster et al., 1987; Snyder-Keller and Costantini, 1996; Nishikawa et al., 1999).

Staining for DARPP-32, a relatively late marker of MSN differentiation and patch organization, reveals striking differences between the wild-type and Ctip $2^{-/-}$striatum. In the wild-type P0 striatum, DARPP-32 is expressed primarily in earlier born MSN that form the distinctive patches (Fig. $4 E, E^{\prime}$ ). In contrast, in the Ctip $2^{-/-}$mutant, only occasional small clusters of neurons express DARPP-32 at extremely low levels; these rare neurons are usually located near the subcallosal streak of the Ctip $2^{-/-}$striatum (Fig. $4 F$, arrowhead). Other than these rare neurons, the Ctip2 $2^{-/-}$striatum is almost completely devoid of DARPP-32 expression (Fig. $4 F, F^{\prime}$ ), indicating that Ctip2 might directly or indirectly regulate DARPP-32 expression in MSN.

Labeling of the Ctip2 $2^{-/-}$striatum by Reelin, MOR1, and GluR1 (all markers of MSN of the patch compartment) (Fig. $4 H, J, L)$ reveals absence of the distinct patches that are identified in wild-type striatum (Fig. 4G, $I, K$ ). Similarly, MAP2 expression is much more homogeneous in Ctip2 null mutant striatum than in wildtype striatum (Fig. $4 M, M^{\prime}$ ), usually with only one or two large areas of dense staining in the subcallosal streak (Fig. $4 N, N^{\prime}$ ). These data indicate that striatal patches do not develop normally in the absence of Ctip2 function.

Interestingly, MOR1 and GluR1 labeling reveal large, abnormal cellular aggregates in mutant striatum (Fig. $4 \mathrm{~J}, \mathrm{~L}$, arrowhead). The absence of DARPP-32 expression in these large cellular aggregates, which are quite different in shape and size from striatal patches in the wild-type, led us to investigate whether they are composed of patch neurons; we find that they are not. BrdU injection at E12.5, during peak production of patch neurons, allowed us to distinguish patch from matrix neurons, which are predominantly born at E17.5 (Marchand and Lajoie, 1986; van der Kooy and Fishell, 1987). At P0, BrdU clearly labels the developing patches in the wildtype striatum (Fig. 4O, arrows). In contrast, early born neurons in the Ctip $2^{-/}$striatum are substantially more homogeneous in distribution (Fig. 4P). These results strongly suggest that the large cellular aggregates detected by MOR1 and GluR1 labeling are not MSN patches, and confirm that, in the absence of Ctip2, striatal patches do not form properly. This is not attributable to early migrational arrest 
because we did not find MSN arrested in the SVZ of the Ctip2 $2^{-/}$mice. Additionally, there was no significant difference in the number of BrdU-positive cells born at E12.5 that migrated into the striatum between Ctip2 ${ }^{-1-}[67.6 \pm 2.9$ (SEM), $n=3$ ]; wildtype, $[71.5 \pm 3.3(\mathrm{SEM}), n=3]$ mice, further indicating that abnormalities in patch formation are not caused by the overt loss of MSN or abnormal migration of MSN into the striatum.

MSN neurons of the matrix also display abnormalities in differentiation. Like the patch neurons, they fail to express DARPP-32 and Chrm4 and exhibit decreased levels of FOXP1 expression. However, levels of the matrix-specific marker Ebf1 are not grossly different in the Ctip $2^{-/-}$striatum, indicating that MSN of the matrix still maintain some of their typical differentiation markers in the absence of Ctip2 (Fig. 4Q,R).

To investigate whether decreased survival of MSN might account for the abnormalities in MSN differentiation, we examined Ctip2 $2^{-/}$striatum to determine whether there is an increase in cell death compared with wild-type striatum. Although we found that there is an increased level of cell death in the Ctip $2^{-1-}$ striatum (supplemental Fig. 2A-L, available at www.jneurosci.org as supplemental material), it is limited to the dorsal aspect of the mutant striatum and is not widespread enough to account for the broadly distributed phenotypic changes in MSN development that we observe. All together, these data demonstrate that Ctip2 is required for the development and maturation of MSN, and for the proper compartmentalization of MSN into patches and matrix.

\section{Abnormal differentiation of MSN is associated with changes in gene expression in the striatum of Ctip $2^{-/-}$ mice}

To investigate the molecular mechanisms that underlie Ctip2-dependent differentiation of MSN and that underlie the patchmatrix disorganization in the mutant striatum, we directly compared gene expression between wild-type and mutant striatum at P0. Because CTIP2-expressing MSN constitute $90-95 \%$ of the neurons within the striatum, we reasoned that we should be able to detect changes in medium spiny neuron gene expression in Ctip2 null mutants using microarrays. We microdissected out small regions of striatum at matched locations in wild-type and Ctip2 $2^{-/-} \mathrm{mu}-$ tant littermates at P0 (see Materials and Methods), and used them in three independent microarray experiments. We selected the 153 most significant genes (see Materials and Methods) and further analyzed them to identify a smaller set of genes of potentially high biological relevance (supplemental Table 2, available at www.jneurosci.org as supplemental material).
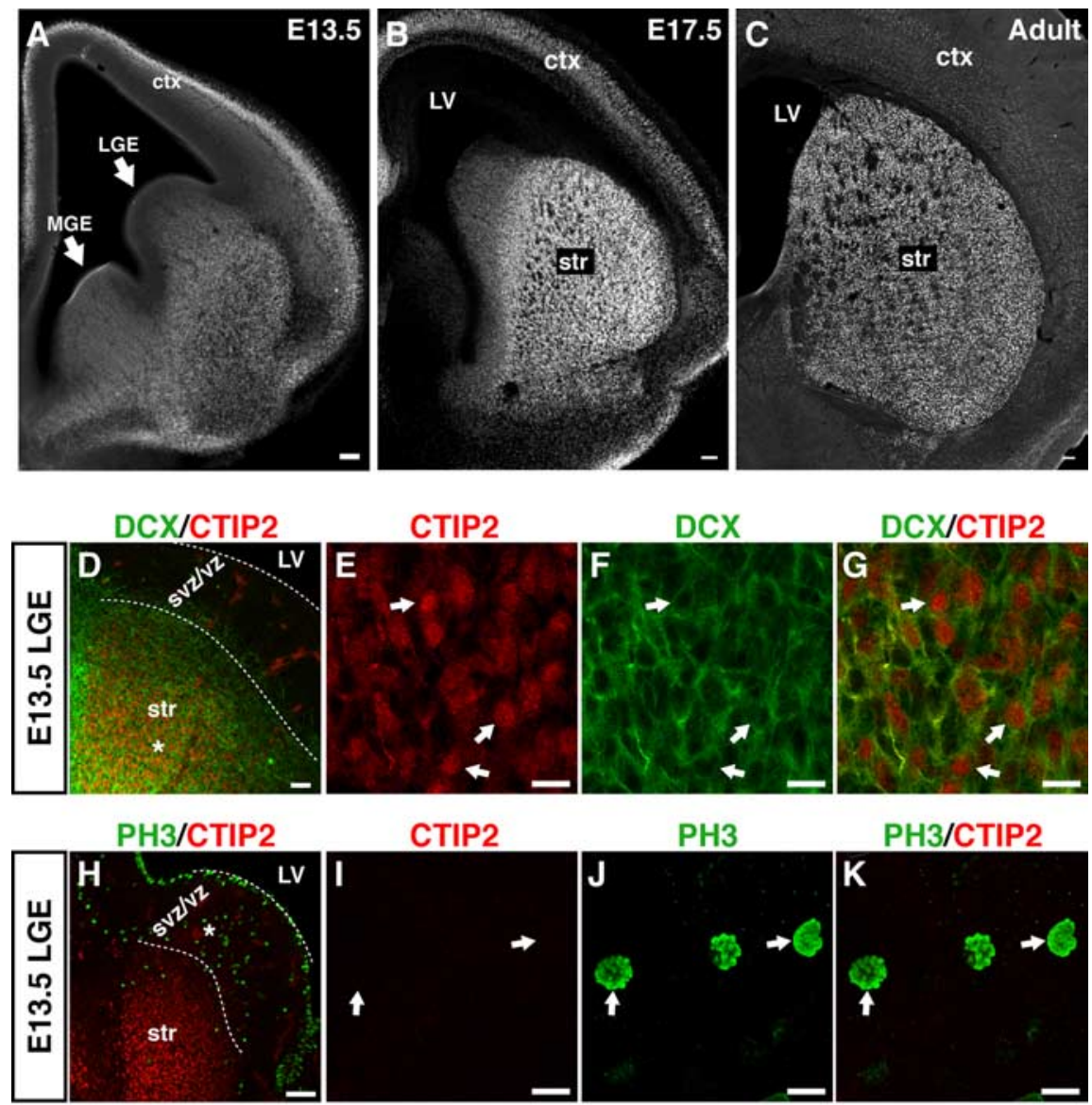

РH3/CTIP2
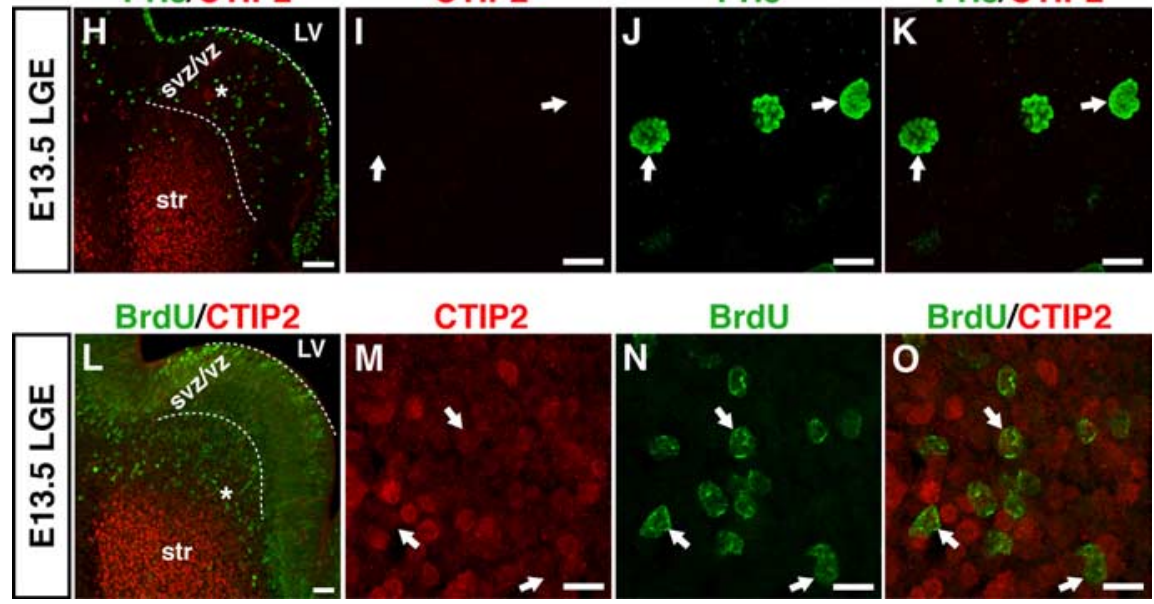

Figure 3. CTIP2 is expressed in postmitotic MSN during development and maintained in mature MSN. $A$, CTIP2 expression at E13.5 in coronal section. $\boldsymbol{B}$, AtE17.5, CTIP2 is expressed at high levels in the striatum. C, CTIP2 continues to be expressed in mature MSN across the entire striatum. D, Confocal photograph of E13.5 LGE showing postmitotic DCx- (green) and CTIP2-expressing (red) MSN in the mantle zone. $\boldsymbol{E}, \boldsymbol{F}$, High-magnification confocal photographs showing colocalization of CTIP2 (E) and Dcx $(\boldsymbol{F})$ expression in the area indicated in $\boldsymbol{D}$ (asterisk). $\boldsymbol{G}$, Merged image of $\boldsymbol{E}$ and $\boldsymbol{F}$. $\boldsymbol{H}$, Confocal photograph of E13.5 LGE showing PH3-positive (green) progenitors in the VZ/SVZ and CTIP2 (red) negative cells in the same areas. I, J, High-magnification confocal photograph in the area indicated in $\boldsymbol{H}$ (asterisk), showing that PH3-positive nuclei $(\boldsymbol{J})$ do not express (TIP2 $(\boldsymbol{I}) . \boldsymbol{K}$, Merged image of $\boldsymbol{I}$ and $\boldsymbol{J}$. $\boldsymbol{L}$, Confocal photograph of E13.5 LGE, showing BrdU-positive (green) progenitors in the VZ/SVZ (labeled via BrdU pulse), and CTIP2-negative (red) cells in the same areas. $\boldsymbol{M}, \boldsymbol{N}$, High-magnification confocal photographs in the area indicated in $\boldsymbol{L}$ (asterisk), showing that BrdU-positive nuclei $(\boldsymbol{N})$ do not express CTIP2 (M). 0 , Merged image of $\boldsymbol{M}$ and $\boldsymbol{N}$. ctx, Cortex; str, striatum; MGE, medial ganglionic eminence; LV, lateral ventricle. Scale bars: $\boldsymbol{A}-\mathbf{C}, 100 \mu \mathrm{m} ; \boldsymbol{D}, \boldsymbol{H}, \boldsymbol{L}, 40 \mu \mathrm{m} ; \boldsymbol{E}-\mathbf{G}, \boldsymbol{I}-\boldsymbol{K}, \boldsymbol{M}-\mathbf{0}, 10 \mu \mathrm{m}$.

To verify the microarray data and define the distribution of the identified genes in the striatum, we performed in situ hybridization or immunohistochemistry for 12 selected genes: PlexinD1, Ngef, Nectin-3, Kcnip2, Pcp4L1, Neto1, Basonuclin 2, Fidgetin, Semaphorin $3 e$, Secretagogin, Unc5d, and Neurotensin. We find that all of these genes are either specifically downregulated (Plexin-D1, Ngef, Nectin-3 Kcnip2, Pcp4L1, Neto1), or upregulated (Basonuclin 2, Fidgetin, Semaphorin 3e, Secretagogin, Unc5d, Neurotensin), in the Ctip $2^{-1-}$ striatum, confirming and extending the microarray results (Fig. 5). Three genes, Plexin-D1, Ngef, and Nectin-3, appear to be broadly expressed in both the patch and matrix compartments of the wild-type, but nearly ab- 

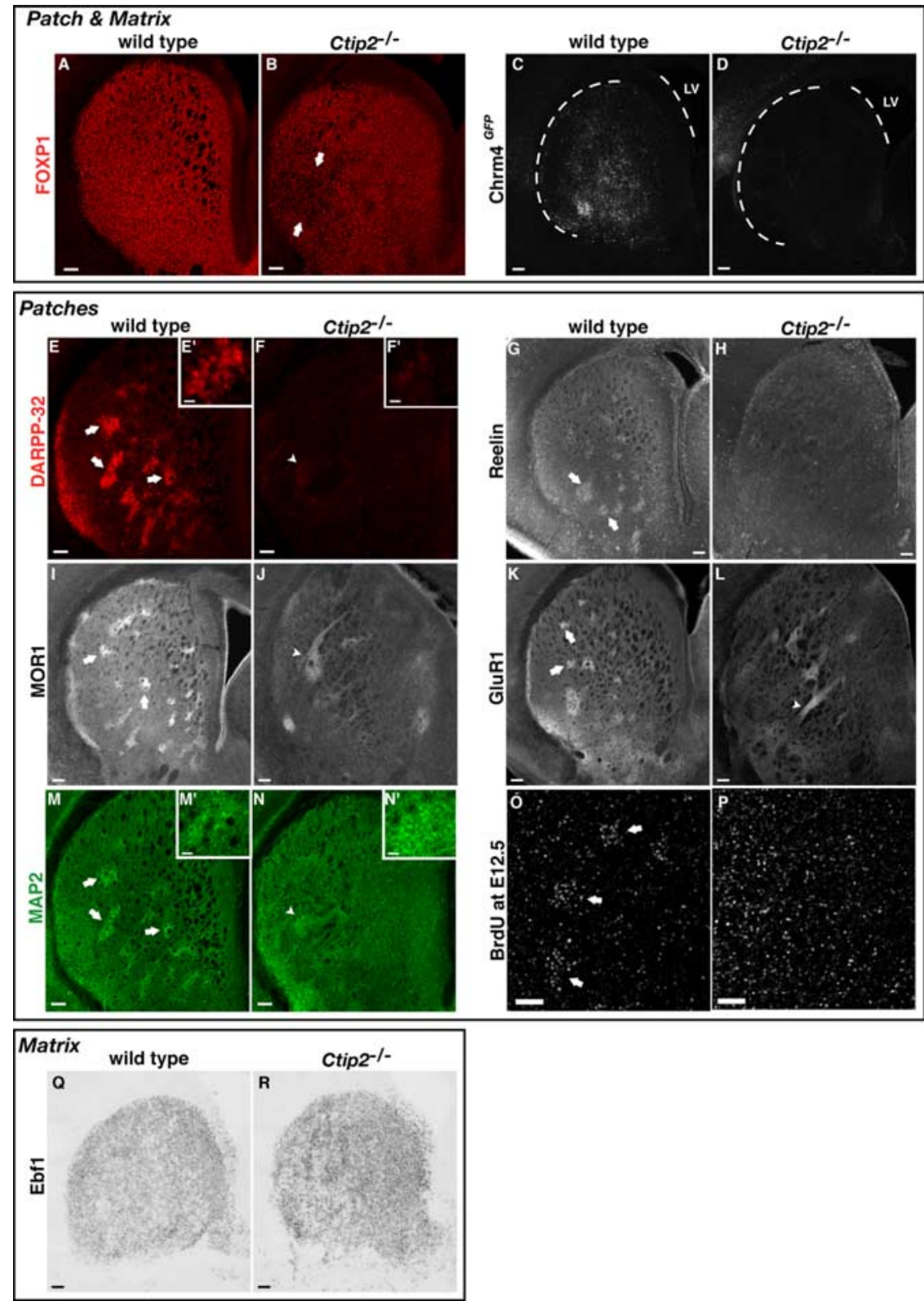

Figure 4. MSN in Ctip2 ${ }^{-1-}$ striatum fail to aggregate into patches and exhibit abnormalities in gene expression. $A-D$, Coronal sections of wild-type $(\boldsymbol{A}, \boldsymbol{C})$ and $C$ tip $2^{-\prime-}(\boldsymbol{B}, \boldsymbol{D})$ striatum at P0, showing that FOXP1 expression is decreased and Chrm 4 is virtually absent from both patch and matrix MSN across the entire striatum in Ctip2 mutants with several distinct areas exhibiting a more severe decrease in F0XP1 expression ( $\boldsymbol{B}$, arrows). $\boldsymbol{E}-\boldsymbol{P}$, Coronal sections of wild-type and $\mathrm{Ctip}^{-/-}$striatum at P0 stained with patch-specific markers. $\boldsymbol{E}$, DARPP-32 staining of a coronal section through wild-type striatum reveals many developing striatal patches that are stained intensely for DARPP-32.F, In contrast, DARPP-32 expression is dramatically decreased in the Ctip2 mutant striatum, in which DARPP-32 is expressed at very low levels by only a small number of cells in lateral striatum (arrowhead; and higher magnification in $\boldsymbol{F}$ ). $\boldsymbol{G}$, Reelin staining in wild-type striatum reveals many developing patches (arrows). $\boldsymbol{H}$, In contrast no distinct patches are identified in the mutant striatum when stained for Reelin. I, MOR1 staining in wild-type striatum reveals many developing striatal patches of typical morphology. $J$, In contrast, the number of striatal patches is greatly decreased in the Ctip2 $^{-1-}$ striatum, with the appearance of large cell aggregates of abnormal morphology that are distinct from typical patches (arrowhead). $\boldsymbol{K}$, Similarly, GluR1 staining of wild-type striatum reveals developing striatal patches. $\boldsymbol{L}$, In contrast, the number of striatal patches detected in matched sections from Ctip2 ${ }^{-1-}$ striatum is greatly decreased, and large cellular aggregates of abnormal morphology appear (arrowhead). $\boldsymbol{M}, \boldsymbol{N}, \mathbf{M A P}$-2 staining of the same sections that are shown in $\boldsymbol{E}$ and $\boldsymbol{F}$, respectively. $\boldsymbol{M}$, MAP2 is expressed in cells throughout the wild-type striatum, with the highest expression levels in developing striatal patches (arrows; and higher magnification image in $\boldsymbol{M}$ ). $\boldsymbol{N}$, In contrast, a matched section from a Ctip2 mutant stained for MAP2 shows that the number of striatal patches is greatly decreased (arrowhead), and patch morphology is abnormal in the Ctip $2^{-}$ striatum. $\mathbf{O}, \boldsymbol{P}$, BrdU-stained coronal sections from E19.5 wild-type $(\mathbf{O})$ and matched $\left(\mathrm{Ctip}^{-/-}(\boldsymbol{P})\right.$, labeled by a single injection of $\mathrm{BrdU}$ at E12.5. O, Wild-type striatum cells containing nuclei that are intensely BrdU positive (indicating a birthdate of E12.5) cluster together (arrows). $\boldsymbol{P}$, In contrast, no aggregation of BrdU-positive cells is observed in Ctip2 $2^{-/}$striatum, indicating that patch neurons do not aggregate, and that the abnormal cell aggregates shown in $\mathbf{J}$ and $\mathbf{L}$ do not contain patch MSN. $\mathbf{Q}, \boldsymbol{R}$, In situ hybridization on wild-type $(\boldsymbol{Q})$ and ttip $^{-1-}(\boldsymbol{R})$ striatum showing comparable levels of Ebf1, a marker of matrix MSN. Scale bars: $A-R, 100 \mu \mathrm{m}, E^{\prime}, F^{\prime}, M^{\prime}, N^{\prime}, 20 \mu \mathrm{m}$. sent from the mutant striatum, further indicating that both patch and matrix MSN exhibit widespread and dramatic abnormalities in differentiation in the absence of Ctip2. Three genes, Kcnip2, Pcp4L1 and Neto1, appear to be highly expressed in the striatal patch compartment in the wildtype, and thus our results suggest that these genes are newly identified striatal patch markers. In agreement with our previous finding that loss of Ctip2 results in abnormal MSN differentiation and failure of striatal patch aggregation, all of the patch markers identified here exhibit dramatically decreased levels of expression in the Ctip $2^{-/-}$mice (Fig. 5D-F). Three genes, Secretagogin, Unc5d, and Neurotensin, show an intriguing spatial distribution; they are expressed within large cellular aggregates in the mutant striatum that are not found in wild-type striatum (Fig. $5 J-L)$. Together, these data demonstrate that loss of Ctip2 causes substantial changes in gene expression in the mutant striatum, and provide a first molecular foundation for understanding the role of Ctip2 in MSN differentiation, striatal patch formation, and striatal cellular organization in vivo.

Failure of striatal patch aggregation is associated with abnormal dopaminergic innervation of the striatum in Ctip2 $2^{-}$ mice

We next investigated the connectivity of nigrostriatal afferents, which normally target the striatal patches, and observed clear abnormalities in the distribution and organization of these afferents at P0. We immunostained nigrostriatal afferent axons for tyrosine hydroxylase $(\mathrm{TH})$ in wild-type and mutant striatum at E15.5 and P0. In P0 wildtype striatum, high levels of TH labeling colocalize with the striatal patches (Fig. $6 \mathrm{~B}$, arrows), whereas $\mathrm{TH}$ labeling is more diffuse and highly disorganized in the striatum of Ctip $2^{-/-}$mice (Fig. 6F). Closer examination of the pattern and local distribution of $\mathrm{TH}^{+}$ input in mutant striatum clearly highlights entire regions that are completely devoid of $\mathrm{TH}^{+}$input (Fig. $6 \mathrm{~F}$, arrowheads). These areas are highly reminiscent in size, location, and distribution of the ectopic cell aggregates that we identified by Secretagogin, Unc5d, and Neurotensin labeling (Fig. 5J-L). To investigate whether $\mathrm{TH}^{+}$axons are repelled from the same aggregates that express high levels of secretagogin, we colabeled wild-type and mutant striatum with $\mathrm{TH}$ and secretagogin, and, strikingly, found that $\mathrm{TH}-$ expressing nigrostriatal afferents do not invade secretagogin-positive clusters (Fig. 6F$H)$, strongly suggesting that these cellular 
aggregates are not composed of MSN. Because TH innervation of the striatum at E15.5 (i.e., before patch aggregation) is initially normal (Fig. 6A,E), we conclude that the lack of patch formation within the striatum is responsible for the observed abnormal distribution of nigrostriatal afferents at P0. Additionally, we find that Ctip2 is not expressed in nigrostriatal neurons of the substantia nigra pars compacta (supplemental Fig. 4A-D, available at www.jneurosci.org as supplemental material), the origin of the TH-positive axons that synapse onto the patches, demonstrating that the observed abnormalities in patch formation in the mutant are not secondary to abnormal nigrostriatal neurons.

\section{Ectopic non-MSN cellular aggregates populate the Ctip $2^{-/-}$striatum}

The observation that $\mathrm{TH}^{+}$afferents do not innervate the clusters of Secretagogin expressing cells suggested to us that the clusters might represent ectopic cells that migrated into the striatum of the Ctip $2^{-/-}$ mutant. These cell clusters are highly reminiscent of the dysmorphic GluR1-positive and MOR1-positive cellular aggregates detected in the mutant striatum (Fig. $4 J, L$ ). In fact, the large Secretagogin clusters colocalize with the GluR1-expressing aggregates, although they do not colocalize with MOR1-expressing aggregates (supplemental Fig. 3, available at www.jneurosci.org as supplemental material). Secretagogin-positive aggregates are also coincident with areas of reduced FOXP1 expression (Fig. 7A-C, arrows), further supporting the interpretation that they are not composed of MSN. Confocal analysis at the single-cell level within large Secretagogin-positive aggregates indicates that the majority of Secretagogin-positive cells do not express the MSN marker FOXP1 (Fig. 7D-F). Additionally, the secretagogin aggregates are largely not born at E12.5, the peak of patch MSN neurogenesis, as shown by lack of colocalization with BrdU labeling from an E12.5 pulse (Fig. 7G-I). Together, these data indicate that the aggregates are not composed of medium spiny neurons and raise the possibility that the cells that constitute them might have ectopically migrated into the Ctip $2^{-/-}$striatum. In further support of this hypothesis, we observed similar clusters of cells expressing Semaphorin 3E (Fig. 5I), Unc5d (Fig. $5 \mathrm{~K}$ ), Neurotensin (Fig. 5L), and Neuropilin 1 (Fig. 8 F) within the mutant striatum.

We next examined the location of Secretagogin expressing cells during development in the wild-type and Ctip $2^{-1-}$ brain to elucidate the developmental and spatial origin of the heterotopic aggregates. Throughout development, Secretagogin expression is
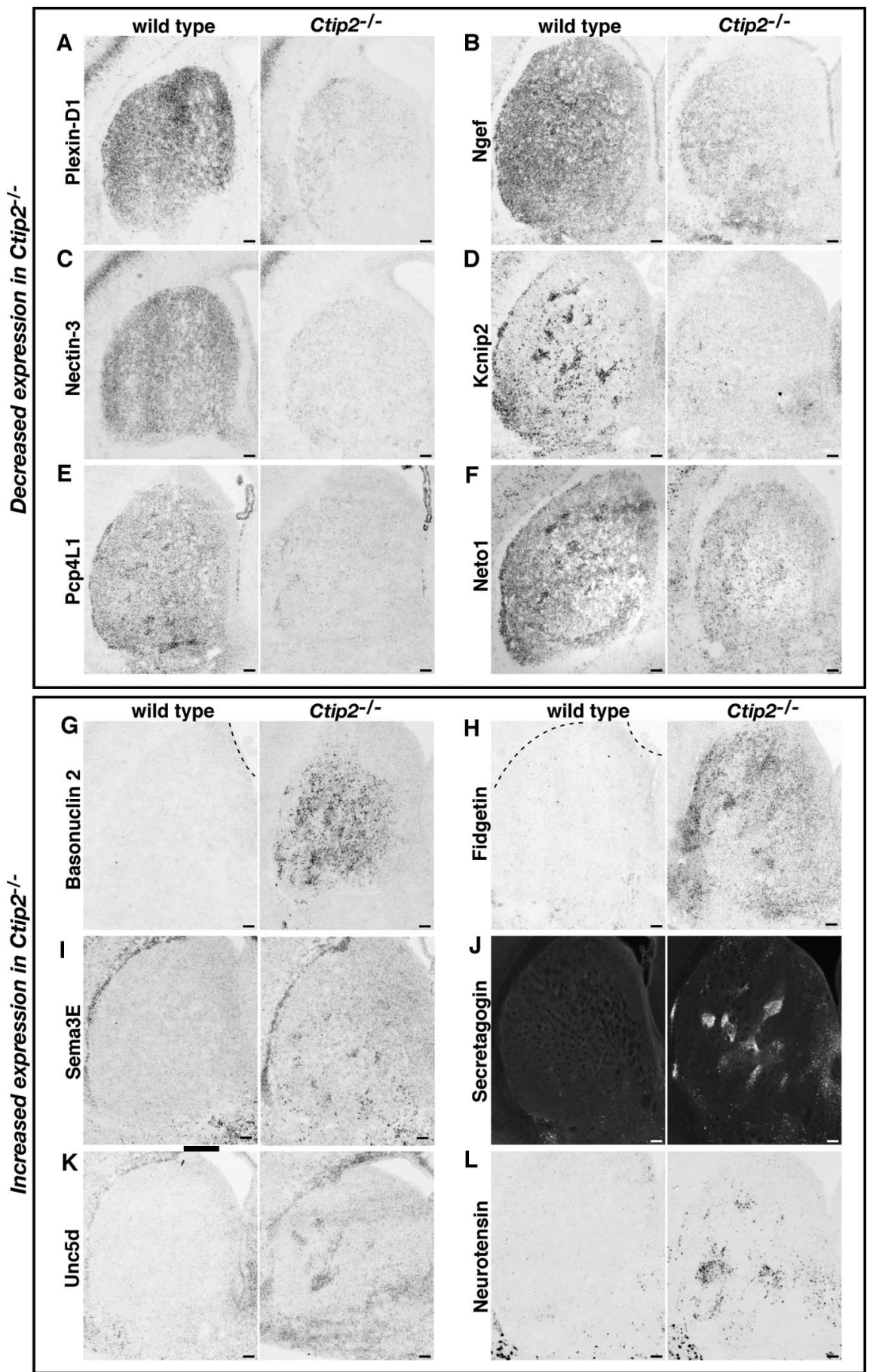

Figure 5. Changes in gene expression in the striatum of $\mathrm{Ctip}^{-1-}$ mice. $A-L$, In situ hybridizations on coronal sections from wild-type and Ctip ${ }^{-/-}$striatum at P0, showing genes with decreased expression $(\boldsymbol{A}-\boldsymbol{F})$, or increased expression $(\boldsymbol{G}-\boldsymbol{L})$ within the striatum of Ctip2 $2^{-/-}$mice. Differences in gene expression are caused by a true, striatum-specific effect of Ctip2 loss on gene regulation, as indicated by comparable expression of these genes in other regions of the brain, including the cortex (Plexin-D1, Nectin-3,Neto1) $(\boldsymbol{A}, \boldsymbol{C}, \boldsymbol{F})$, the choroid plexus $(P(p 4 L 1)(\boldsymbol{E})$, the ependymal layer $(\operatorname{Ngef})(\boldsymbol{B})$, and additional cell populations outside the striatum (Kcnip2, secretagogin, Neurotensin) $(\boldsymbol{D}, \boldsymbol{J}, \boldsymbol{L})$. Scale bars: $\boldsymbol{A}-\boldsymbol{L}, 100 \mu \mathrm{m}$.

limited to just a few areas of the brain. Interestingly, at E15.5, when MSN are starting to form the striatum, there is a population of secretagogin expressing cells located just ventral to the developing striatum (Fig. 8A, $B$, arrows). At P0, secretagogin cells are located in the olfactory bulb, as well as ventral to the striatum, in both the wild-type and Ctip $2^{-/-}$mutant mice (Fig. 8C,D, arrows), whereas only the mutant striatum contains secretagogin 
TH - E15.5
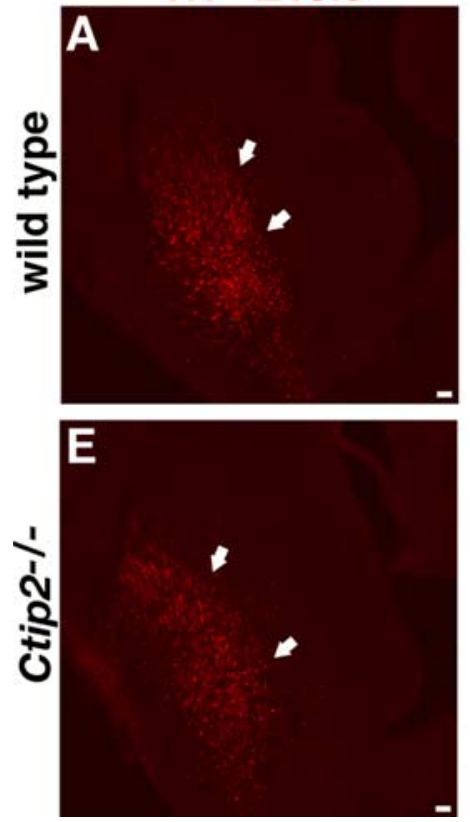

TH - PO
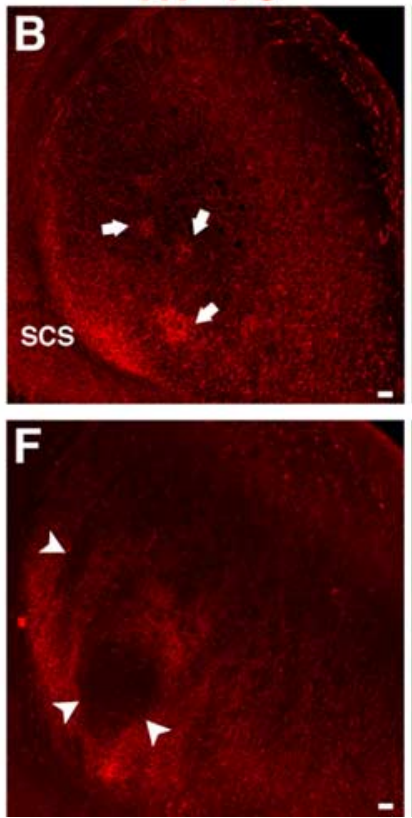

Secretagogin
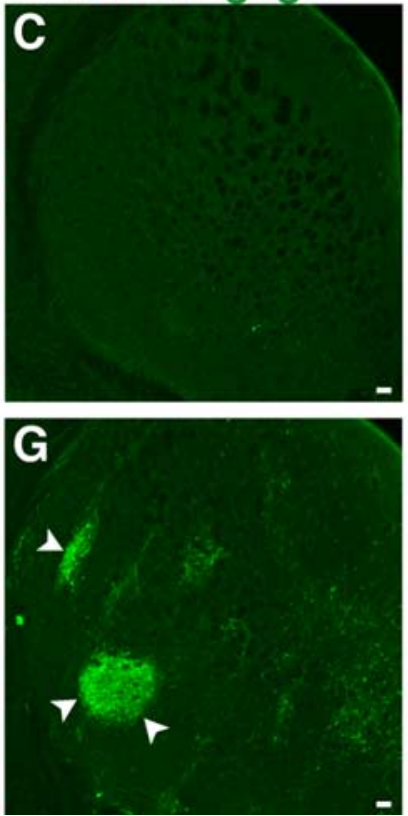

TH/Secretagogin
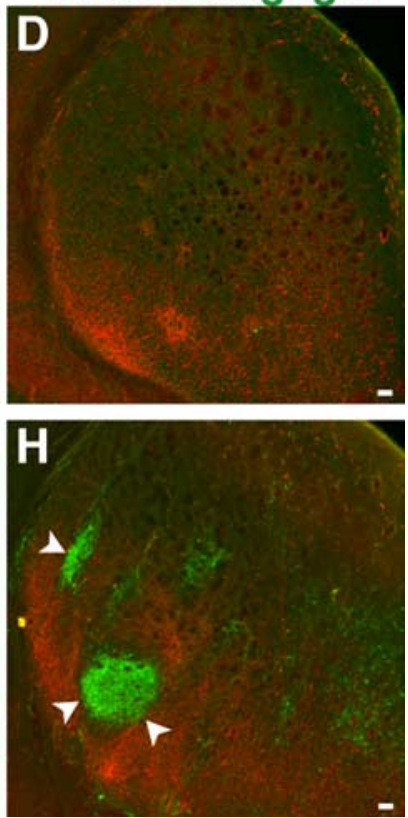

Figure 6. Abnormal nigrostriatal innervation of the Ctip $2^{-/-}$striatum. $\boldsymbol{A}, \boldsymbol{E}$, Coronal sections of wild-type $(\boldsymbol{A})$ and mutant $(\boldsymbol{E})$ developing striatum at E15.5 stained with $\mathrm{TH}$, showing comparable distribution of TH innervation at this age, before aggregation of the patches occurs. $\boldsymbol{B}-\boldsymbol{D}, \boldsymbol{F}-\boldsymbol{H}$, Coronal sections of wild-type $(\boldsymbol{B}-\boldsymbol{D})$ and $C$ tip2 ${ }^{-1-}(\boldsymbol{F}-\boldsymbol{H})$ striatum at P0 stained with TH and secretagogin. $\boldsymbol{B}$, TH staining of wild-type striatum reveals distinct colocalization with developing striatal patches (arrows). $\boldsymbol{F}$, In contrast, TH staining is diffuse and disorganized in Ctip $2^{-/}$striatum, showing no colocalization with patches, and delineating distinct areas of TH depletion (arrowheads). $\boldsymbol{C}$, Secretagogin staining reveals no cells are labeled in wild-type striatum. $\boldsymbol{D}$, Merged image of $\boldsymbol{B}$ and $\boldsymbol{C} . \mathbf{G}$, In contrast, large aggregates of secretagogin positive cells are present in Ctip $2^{-/-}$striatum; these aggregates exclude TH innervation $(\boldsymbol{H})$. Scale bars: $\boldsymbol{A}-\boldsymbol{H}, 50 \mu \mathrm{m}$.

cellular aggregates (Fig. 8D, arrowhead). These cellular aggregates are present as early as E17.5 (data not shown). Together, these data suggest that the population of cells ventral to the striatum might represent the source of secretagogin-expressing cells that later infiltrate the striatum in the absence of CTIP2.

In agreement with the presence of ectopic cellular aggregates in the mutant striatum, our microarray data identified multiple molecules known to mediate cellular repulsion that are differentially expressed within the Ctip2 mutant striatum, including Plexin-D1, Semaphorin 3E, and Neuropilin 1 (supplemental Table 2, available at www.jneurosci.org as supplemental material) (Marin et al., 2001; Gu et al., 2005; Watakabe et al., 2006). Although the mutant striatum has dramatically decreased levels of Plexin-D1 and possesses ectopic clusters of cells expressing its ligand, Semaphorin 3E, the loss of Plexin-D1 alone is not sufficient to recapitulate the phenotype seen in the absence of Ctip2 (supplemental Fig. 5, available at www.jneurosci.org as supplemental material). This is consistent with the current model of Semaphorin $3 \mathrm{E}$ acting solely as a secreted ligand. To investigate the role of Neuropilin 1, we examined its expression by in situ hybridization and found that it is expressed in ectopic clusters of cells within them mutant (Fig. $8 F$, arrows) that are not present in the wild-type (Fig. $8 E$ ). However, the levels of Semaphorin $3 A$ and Semaphorin $3 F$, which are known to mediate repulsion of Neuropilin 1 cells migrating around the striatum (Marin et al., 2001; Tamamaki et al., 2003), were not changed in the mutant striatum. This indicates that abnormalities in the expression of other, yet unidentified, ligands are likely responsible for the presence of the ectopic cells.

\section{Discussion}

Here, we report that CTIP2, a transcription factor that we found previously to play critical lineage-specific roles in corticospinal motor neuron development in the neocortex (Arlotta et al.,
2005), is specifically expressed by striatal medium spiny neurons and is required for the proper differentiation of this important projection neuron type. In the absence of Ctip2, MSN of both the patch and the matrix compartments develop abnormally, as indicated by a dramatic dysregulation of several known and novel striatal genes in $C t i p 2^{-1-}$ striatum. MSN are born in correct number and migrate into the striatum but they fail to aggregate into patches, and afferent dopaminergic innervation, normally targeted to the patches in wild-type striatum, is highly disorganized and entirely repelled from distinct areas within the mutant striatum. The areas of TH depletion coincide with aggregates of ectopic cells that appear to invade the striatum in the absence of Ctip2, and are identified by GluR1 and Secretagogin labeling. These cellular aggregates are not striatal patches: they are much larger and morphologically distinct from developing P0 wildtype patches; they are largely devoid of patch markers (e.g., DARPP-32 and Reelin); they repel (or are repelled by) afferent dopaminergic input from the substantia nigra; and they are not composed of cells born at E12.5, the period of peak neurogenesis of patch MSN. Together, these data indicate that CTIP2 plays an essential role in the development of MSN in the striatum, critically controlling patch-matrix compartmentalization of MSN in vivo.

\section{CTIP2-mediated regulation of medium spiny neuron development}

CTIP2 expression is first detected at the interface between the $\mathrm{SVZ}$ and the mantle zone in Doublecortin-expressing immature neurons, indicating that CTIP2 is expressed in early postmitotic MSN. Therefore, the observed abnormalities in MSN differentiation in Ctip $2^{-/-}$mice are very likely caused by defects in postmitotic maturation and connectivity of MSN, rather than to an earlier fate specification defect in MSN progenitors. This neuron type-specific and temporal expression of CTIP2 in the striatum 
shows remarkable parallels to that in the neocortex, where CTIP2 is expressed at high levels in postmitotic neurons in the cortical plate and not in progenitors in the VZ/SVZ (Arlotta et al., 2005). Within the cortex, CTIP2 exhibits lineage-restricted high-level expression in corticospinal and cortico-brainstem projection neurons. Similarly, within the striatum, CTIP2 is restricted to MSN (the striatal output projection neurons), together suggesting that CTIP2 controls lineage-restricted pathways of gene regulation in specific projection neuron populations of the brain.

Within the pathways of medium spiny neuron specification and differentiation, Ctip2 likely acts downstream of genes such as Gsh2, Dlx1/2, Mash1, and Islet1, which have been shown previously to play important roles in the specification of the ventral telencephalic identity of progenitors in the VZ and/or SVZ (Anderson et al., 1997a; Casarosa et al., 1999; Yun et al., 2001; Stenman et al., 2003). Whereas Ctip2 expression is first detected in migrating MSN, Gsh2, Dlx1/2, Mash1, and Islet1 are expressed much earlier in the progenitors that give rise to MSN. Similar to Ctip $2^{-/-}$ mice, Gsh $2^{-/-}$mice also show a decrease in DARPP-32 expression and abnormal patch formation. However, this phenotype is secondary to changes in the progenitor population in the VZ of the Gsh $2^{-1-}$ LGE (Corbin et al., 2000; Toresson et al., 2000b; Toresson and Campbell, 2001). In the future, it will be interesting to investigate directly if and how CTIP2 interacts with each of these other transcription factors in controlling the development of medium spiny neurons.

Interestingly, CTIP2 and the closely related transcription factor CTIP1 can both interact directly with members of the chicken ovalbumin upstream promoter transcription factor (COUP-TF) family of transcription factors (Avram et al., 2000), and they have both been reported to act as transcriptional repressors in vitro. However, COUP-TF1 and CTIP2 patterns of gene expression are not completely overlapping in the brain, suggesting the possibility that CTIP2 may confer lineage-specificity to COUP-TF1mediated gene regulation. Like Ctip2, Ctip1 is expressed at high levels in the striatum during development (Leid et al., 2004) in a pattern consistent with expression in MSN. Because the Ctip1 and Ctip2 genes share a high degree of homology (Avram et al., 2000, 2002), the presence of Ctip1 might partially compensate for the loss of Ctip2 in Ctip2 $2^{-/-}$mutants, resulting in a more mild phenotype. Consistent with this hypothesis, we found that Ctip1 exhibited increased expression in the Ctip 2 mutant by microarray (supplemental Table 2, available at www.jneurosci.org as supplemental material).

Nevertheless, in the absence of Ctip2 alone, there are drastic changes in the expression of many genes, several of which appear to be novel identifiers of the patch and/or matrix compartments
Secretagogin

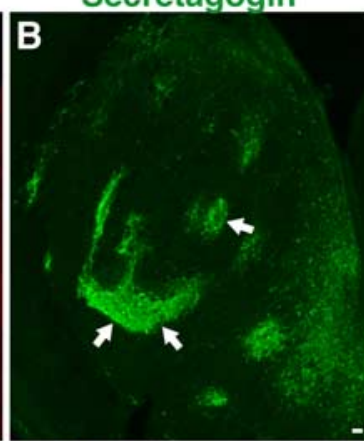

FOXP1/Secretagogin
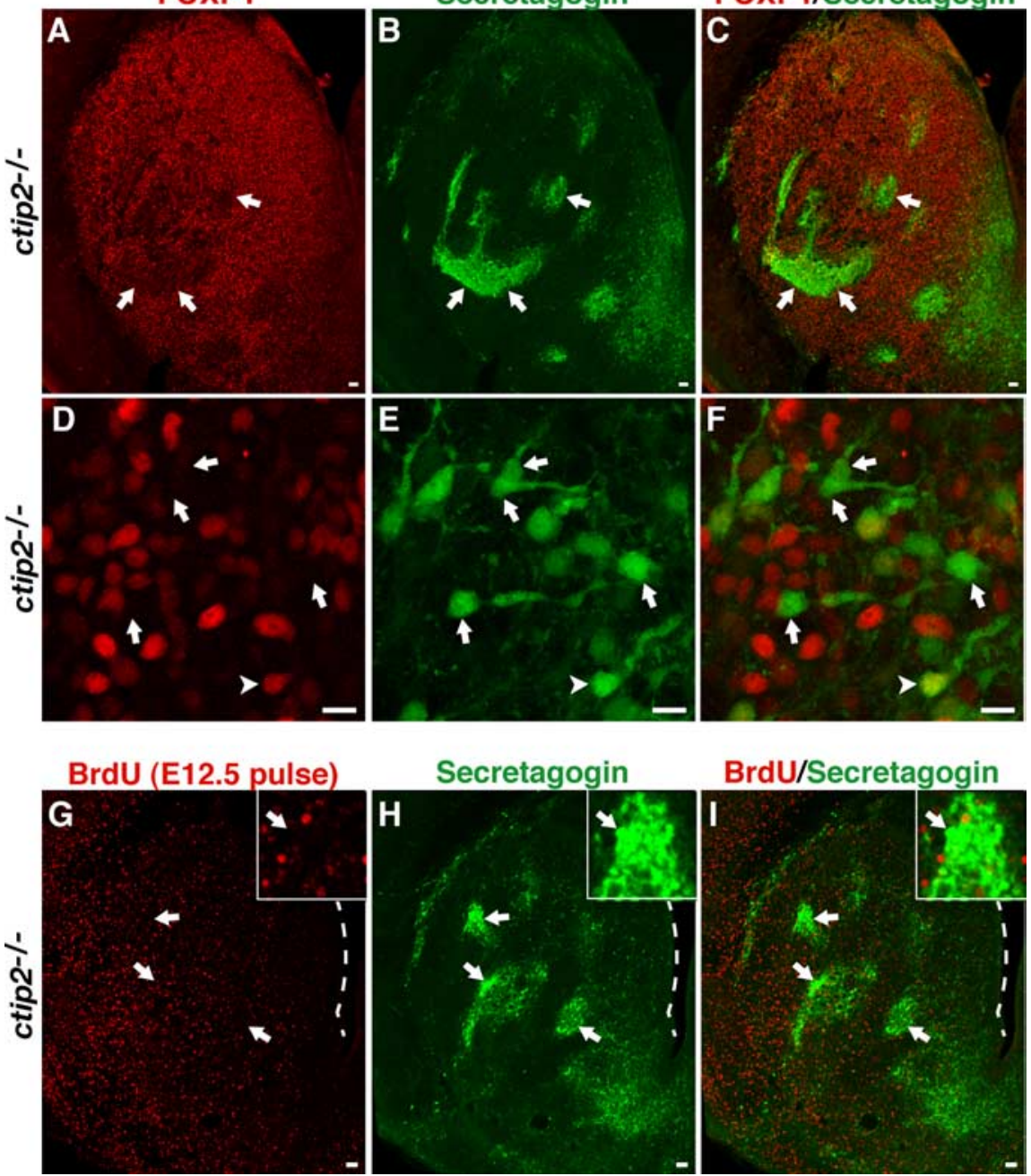

BrdU/Secretagogin

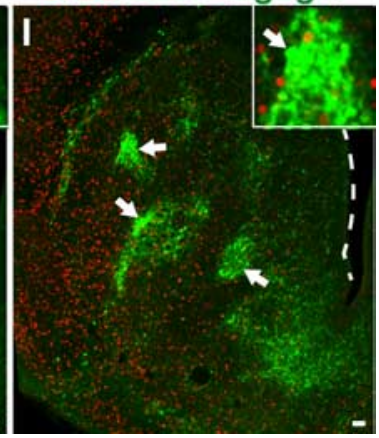

striatum. A-C, Coronal sections through Ctip2 $2^{-1}$ striatum, showing colocalization of large secretagogin-positive aggregates, with areas of highly reduced F0XP1 expression (arrows). $\boldsymbol{D}-\boldsymbol{F}$, Confocal images of selected secretagogin-positive cells from the large aggregates shown in $\boldsymbol{B}$, showing that a small percentage of the secretagogin-positive cells express FOXP1, a marker of MSN (arrows), whereas the majority do not express E12.5) $(\boldsymbol{G})$ and secretagogin $(\boldsymbol{H})$, showing that secretagogin-positive aggregates do not specifically overlap with BrdU labeled cells (arrows) and, thus, are not born at E12.5 (i.e., peak neurogenesis of patch MSN). Insets show enlarged image of aggregate indicated by most dorsal arrow. I, Merged image of $\mathbf{G}$ and $\boldsymbol{H}$. Scale bars: $\boldsymbol{A}-\boldsymbol{C}, \mathbf{G}-\boldsymbol{I}, 50 \mu \mathrm{m}, \boldsymbol{D}-\boldsymbol{F}, 10 \mu \mathrm{m}$.

at P0. The almost complete absence of DARPP-32 expression in the Ctip2 mutants raises the interesting possibility that Ctip2 activates the DARPP-32 gene via binding directly or indirectly (e.g., via COUP-TF1) to the DARPP-32 promoter. Supporting this hypothesis, we identified a CTIP2 consensus binding site that is conserved across species and is located $\sim 6.5 \mathrm{~kb}$ upstream of the Darpp-32 transcription start site. Additionally, we identified a COUP-TF1 consensus binding site located within the first intron of Darpp-32 that is highly conserved across species (Molyneaux et al., unpublished observations). It will be interesting to investigate the ability of CTIP2 and COUP-TF1 to regulate the expression of Darpp-32 via binding to these sites.

Ectopic cellular aggregates in the striatum of Ctip2 $2^{-/-}$mice Although the Ctip2 mutant lacks striatal patches, the mutant striatum does contain large, disorganized aggregates of cells expressing Secretagogin, Neurotensin, or Unc5D. The origin of these cells is unclear. One possibility is that they could be a subpopulation of medium spiny neurons that are exhibiting extremely abnormal 

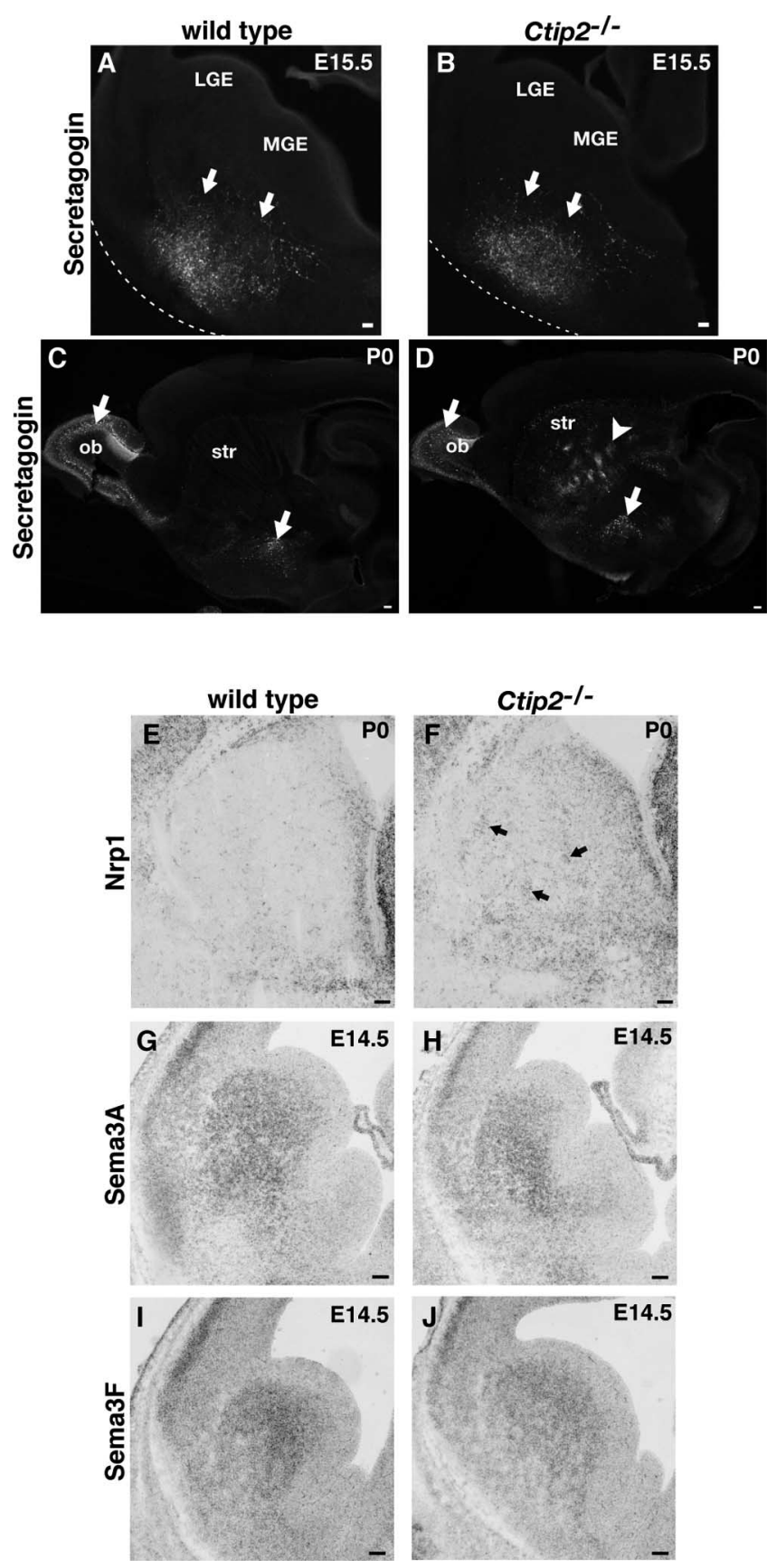

Figure 8. Molecular mechanisms of cellular repulsion are dysregulated in $\mathrm{Ctip}^{-/-}$striatum. $\boldsymbol{A}, \boldsymbol{B}$, Coronal sections of wild-type $(\boldsymbol{A})$ and $\left(\mathrm{Ctip} 2^{-/-}(\boldsymbol{B})\right.$ brain at E15.5, showing comparable distribution of Secretagogin-positive cells at early stages of striatal development. $\boldsymbol{C}, \boldsymbol{D}$, Sagittal/oblique sections of wild-type $(\boldsymbol{C})$ and $\left(\mathrm{Ctip}^{-/-}(\boldsymbol{D})\right.$ forebrain at $\mathrm{PO}$, showing the distribution of Secretagogin-positive cells. C, Wild-type brain shows typical distribution of secretagogin cells ventral to the striatum and in the olfactory bulb (arrows). D, In contrast, large clusters of Secretagogin cells infiltrate the Ctip ${ }^{-/-}$striatum (arrowhead). $\boldsymbol{E}-\boldsymbol{J}$, In situ hybridizations of coronal sections through wild-type $(\boldsymbol{E}, \boldsymbol{G}, \boldsymbol{I})$ and $\mathrm{Ctip}^{-/-}(\boldsymbol{F}, \boldsymbol{H}, \boldsymbol{J})$ striatum at P0, Neuropilin 1 is absent from the wild-type striatum $(\boldsymbol{E})$, but is expressed within cellular aggregates in the mutant striatum ( $\boldsymbol{F}$, arrows). Developing wild-type and $\mathrm{Ctip}^{-/-}$striatum exhibits equivalent levels of Semaphorin $3 A(\boldsymbol{G}, \boldsymbol{H})$ and Semaphorin $3 F(\boldsymbol{I}, \boldsymbol{J})$ expression. str, Striatum; MGE, medial ganglionic eminence; ob, olfactory bulb. Scale bars: $A, B, 50 \mu \mathrm{m} ; C-J, 100 \mu \mathrm{m}$.

patterns of gene expression and aggregation in the absence of Ctip2. However, given their expression of Secretagogin, the largely absent FOXP1 expression, the fact that they are not born during the peak period of patch neurogenesis, and that they ap- pear to repel TH-positive afferents, these aggregates likely consist of cells that have migrated aberrantly into the striatum.

During normal development, striatal neurons repel streams of migrating cells destined for distant locations such as the cortex and olfactory bulb (Marin et al., 2001; Wichterle et al., 2001). Semaphorin $3 A$ and Semaphorin $3 F$ are two ligands expressed in the striatum that are known to mediate repulsion of migrating interneurons destined for the neocortex via interactions with Neuropilin 1 expressed on the surface of the migrating neurons (Marin et al., 2001). Although we found that Neuropilin 1 is expressed at elevated levels within clusters of ectopic cells found in the mutant striatum, we did not detect any differences in striatal expression of Semaphorin $3 A$ and Semaphorin $3 F$ at E14.5. Therefore, additional, yet unidentified diffusible ligands that are dysregulated in the striatum of the mutant must play a central role. Future experiments will seek to clarify the origin of the cellular aggregates and identify the extent of molecules expressed by MSN that mediate cellular repulsion, as well as to further define the mechanisms that mediate Ctip2 control over the development of the medium spiny neuron lineage in vivo.

\section{References}

Albin RL, Young AB, Penney JB (1989) The functional anatomy of basal ganglia disorders. Trends Neurosci 12:366-375.

Anderson KD, Reiner A (1991) Immunohistochemical localization of DARPP-32 in striatal projection neurons and striatal interneurons: implications for the localization of D1-like dopamine receptors on different types of striatal neurons. Brain Res 568:235-243.

Anderson SA, Eisenstat DD, Shi L, Rubenstein JL (1997a) Interneuron migration from basal forebrain to neocortex: dependence on Dlx genes. Science 278:474-476.

Anderson SA, Qiu M, Bulfone A, Eisenstat DD, Meneses J, Pedersen R, Rubenstein JL (1997b) Mutations of the homeobox genes Dlx-1 and Dlx-2 disrupt the striatal subventricular zone and differentiation of late born striatal neurons. Neuron 19:27-37.

Arlotta P, Molyneaux BJ, Chen J, Inoue J, Kominami R, Macklis JD (2005) Neuronal subtype-specific genes that control corticospinal motor neuron development in vivo. Neuron 45:207-221.

Avram D, Fields A, Pretty On Top K, Nevrivy DJ, Ishmael JE, Leid M (2000) Isolation of a novel family of $\mathrm{C}(2) \mathrm{H}(2)$ zinc finger proteins implicated in transcriptional repression mediated by chicken ovalbumin upstream promoter transcription factor (COUP-TF) orphan nuclear receptors. J Biol Chem 275:10315-10322.

Avram D, Fields A, Senawong T, Topark-Ngarm A, Leid M (2002) COUP-TF (chicken ovalbumin upstream promoter transcription factor)interacting protein 1 (CTIP1) is a sequence-specific DNA binding protein. Biochem J 368:555-563.

Banham AH, Beasley N, Campo E, Fernandez PL, Fidler C, Gatter K, Jones M, Mason DY, Prime JE, Trougouboff P, Wood K, Cordell JL (2001) The FOXP1 winged helix transcription factor is a novel candidate tumor suppressor gene on chromosome 3p. Cancer Res 61:8820-8829.

Berger UV, Hediger MA (2001) Differential distribution of the glutamate transporters GLT-1 and GLAST in tanycytes of the third ventricle. J Comp Neurol 433:101-114.

Casarosa S, Fode C, Guillemot F (1999) Mash1 regulates neurogenesis in the ventral telencephalon. Development 126:525-534.

Chang CW, Tsai CW, Wang HF, Tsai HC, Chen HY, Tsai TF, Takahashi H, Li HY, Fann MJ, Yang CW, Hayashizaki Y, Saito T, Liu FC (2004) Identification of a developmentally regulated striatum-enriched zinc-finger gene, Nolz-1, in the mammalian brain. Proc Natl Acad Sci USA 101:2613-2618.

Corbin JG, Gaiano N, Machold RP, Langston A, Fishell G (2000) The Gsh2 homeodomain gene controls multiple aspects of telencephalic development. Development 127:5007-5020.

Deacon TW, Pakzaban P, Isacson O (1994) The lateral ganglionic eminence is the origin of cells committed to striatal phenotypes: neural transplantation and developmental evidence. Brain Res 668:211-219.

Foster GA, Schultzberg M, Hokfelt T, Goldstein M, Hemmings Jr HC, Ouimet CC, Walaas SI, Greengard P (1987) Development of a dopamine- 
and cyclic adenosine $3^{\prime}: 5^{\prime}$-monophosphate-regulated phosphoprotein (DARPP-32) in the prenatal rat central nervous system, and its relationship to the arrival of presumptive dopaminergic innervation. J Neurosci 7:1994-2018.

Fricker-Gates RA, Shin JJ, Tai CC, Catapano LA, Macklis JD (2002) Latestage immature neocortical neurons reconstruct interhemispheric connections and form synaptic contacts with increased efficiency in adult mouse cortex undergoing targeted neurodegeneration. J Neurosci 22:4045-4056.

Gartner W, Lang W, Leutmetzer F, Domanovits H, Waldhausl W, Wagner L (2001) Cerebral expression and serum detectability of secretagogin, a recently cloned EF-hand $\mathrm{Ca}\left({ }^{2+}\right)$-binding protein. Cereb Cortex 11:1161-1169.

Gerfen CR (1992) The neostriatal mosaic: multiple levels of compartmental organization in the basal ganglia. Annu Rev Neurosci 15:285-320.

Gong S, Zheng C, Doughty ML, Losos K, Didkovsky N, Schambra UB, Nowak NJ, Joyner A, Leblanc G, Hatten ME, Heintz N (2003) A gene expression atlas of the central nervous system based on bacterial artificial chromosomes. Nature 425:917-925.

Graybiel AM (2005) The basal ganglia: learning new tricks and loving it. Curr Opin Neurobiol 15:638-644.

Gu C, Yoshida Y, Livet J, Reimert DV, Mann F, Merte J, Henderson CE, Jessell TM, Kolodkin AL, Ginty DD (2005) Semaphorin 3E and plexin-D1 control vascular pattern independently of neuropilins. Science 307:265-268.

Ince E, Ciliax BJ, Levey AI (1997) Differential expression of D1 and D2 dopamine and $\mathrm{m} 4$ muscarinic acetylcholine receptor proteins in identified striatonigral neurons. Synapse 27:357-366.

Irizarry RA, Hobbs B, Collin F, Beazer-Barclay YD, Antonellis KJ, Scherf U, Speed TP (2003) Exploration, normalization, and summaries of high density oligonucleotide array probe level data. Biostatistics 4:249-264.

Ivkovic S, Ehrlich ME (1999) Expression of the striatal DARPP-32/ ARPP-21 phenotype in GABAergic neurons requires neurotrophins in vivo and in vitro. J Neurosci 19:5409-5419.

Jain M, Armstrong RJ, Barker RA, Rosser AE (2001) Cellular and molecular aspects of striatal development. Brain Res Bull 55:533-540.

Kawaguchi Y (1993) Physiological, morphological, and histochemical characterization of three classes of interneurons in rat neostriatum. J Neurosci 13:4908-4923.

Kawaguchi Y, Wilson CJ, Augood SJ, Emson PC (1995) Striatal interneurones: chemical, physiological and morphological characterization. Trends Neurosci 18:527-535.

Kemp JM, Powell TP (1971) The structure of the caudate nucleus of the cat: light and electron microscopy. Philos Trans R Soc Lond B Biol Sci 262:383-401.

Krushel LA, Connolly JA, van der Kooy D (1989) Pattern formation in the mammalian forebrain: patch neurons from the rat striatum selectively reassociate in vitro. Brain Res Dev Brain Res 47:137-142.

Krushel LA, Fishell G, van der Kooy D (1995) Pattern formation in the mammalian forebrain: striatal patch and matrix neurons intermix prior to compartment formation. Eur J Neurosci 7:1210-1219.

Leid M, Ishmael JE, Avram D, Shepherd D, Fraulob V, Dolle P (2004) CTIP1 and CTIP2 are differentially expressed during mouse embryogenesis. Gene Expr Patterns 4:733-739.

Lobo MK, Karsten SL, Gray M, Geschwind DH, Yang XW (2006) FACSarray profiling of striatal projection neuron subtypes in juvenile and adult mouse brains. Nat Neurosci 9:443-452.

Magavi SS, Leavitt BR, Macklis JD (2000) Induction of neurogenesis in the neocortex of adult mice. Nature 405:951-955.

Marchand R, Lajoie L (1986) Histogenesis of the striopallidal system in the rat. Neurogenesis of its neurons. Neuroscience 17:573-590.

Marin O, Yaron A, Bagri A, Tessier-Lavigne M, Rubenstein JL (2001) Sorting of striatal and cortical interneurons regulated by semaphorinneuropilin interactions. Science 293:872-875.

Molyneaux BJ, Arlotta P, Hirata T, Hibi M, Macklis JD (2005) Fezl is required for the birth and specification of corticospinal motor neurons. Neuron 47:817-831.

Moon Edley S, Herkenham M (1984) Comparative development of striatal opiate receptors and dopamine revealed by autoradiography and histofluorescence. Brain Res 305:27-42.

Nishikawa S, Goto S, Hamasaki T, Ogawa M, Ushio Y (1999) Transient and compartmental expression of the reeler gene product reelin in the developing rat striatum. Brain Res 850:244-248.

Olsson M, Campbell K, Wictorin K, Bjorklund A (1995) Projection neurons in fetal striatal transplants are predominantly derived from the lateral ganglionic eminence. Neuroscience 69:1169-1182.

Olsson M, Campbell K, Turnbull DH (1997) Specification of mouse telencephalic and mid-hindbrain progenitors following heterotopic ultrasound-guided embryonic transplantation. Neuron 19:761-772.

Ouimet CC, Greengard P (1990) Distribution of DARPP-32 in the basal ganglia: an electron microscopic study. J Neurocytol 19:39-52.

Ouimet CC, Miller PE, Hemmings Jr HC, Walaas SI, Greengard P (1984) DARPP-32, a dopamine- and adenosine $3^{\prime}: 5^{\prime}$-monophosphate-regulated phosphoprotein enriched in dopamine-innervated brain regions. III. Immunocytochemical localization. J Neurosci 4:111-124.

Ouimet CC, Langley-Gullion KC, Greengard P (1998) Quantitative immunocytochemistry of DARPP-32-expressing neurons in the rat caudatoputamen. Brain Res 808:8-12.

Schmued LC, Hopkins KJ (2000) Fluoro-Jade B: a high affinity fluorescent marker for the localization of neuronal degeneration. Brain Res 874:123-130.

Senawong T, Peterson VJ, Avram D, Shepherd DM, Frye RA, Minucci S, Leid M (2003) Involvement of the histone deacetylase SIRT1 in chicken ovalbumin upstream promoter transcription factor (COUP-TF)interacting protein 2-mediated transcriptional repression. J Biol Chem 278:43041-43050.

Shi C, Zhang X, Chen Z, Sulaiman K, Feinberg MW, Ballantyne CM, Jain MK, Simon DI (2004) Integrin engagement regulates monocyte differentiation through the forkhead transcription factor Foxp1. J Clin Invest 114:408 -418.

Snyder-Keller A, Costantini LC (1996) Glutamate receptor subtypes localize to patches in the developing striatum. Brain Res Dev Brain Res 94:246-250.

Song DD, Harlan RE (1994) Genesis and migration patterns of neurons forming the patch and matrix compartments of the rat striatum. Brain Res Dev Brain Res 83:233-245.

Stenman J, Toresson H, Campbell K (2003) Identification of two distinct progenitor populations in the lateral ganglionic eminence: implications for striatal and olfactory bulb neurogenesis. J Neurosci 23:167-174.

Tamamaki N, Fujimori K, Nojyo Y, Kaneko T, Takauji R (2003) Evidence that Sema3A and Sema3F regulate the migration of GABAergic neurons in the developing neocortex. J Comp Neurol 455:238-248.

Tamura S, Morikawa Y, Iwanishi H, Hisaoka T, Senba E (2004) Foxp1 gene expression in projection neurons of the mouse striatum. Neuroscience 124:261-267.

Tepper JM, Bolam JP (2004) Functional diversity and specificity of neostriatal interneurons. Curr Opin Neurobiol 14:685-692.

Toresson H, Campbell K (2001) A role for Gsh1 in the developing striatum and olfactory bulb of Gsh2 mutant mice. Development 128:4769-4780.

Toresson H, Parmar M, Campbell K (2000a) Expression of Meis and Pbx genes and their protein products in the developing telencephalon: implications for regional differentiation. Mech Dev 94:183-187.

Toresson H, Potter SS, Campbell K (2000b) Genetic control of dorsalventral identity in the telencephalon: opposing roles for Pax6 and Gsh2. Development 127:4361-4371.

Tusher VG, Tibshirani R, Chu G (2001) Significance analysis of microarrays applied to the ionizing radiation response. Proc Natl Acad Sci USA 98:5116-5121.

van der Kooy D, Fishell G (1987) Neuronal birthdate underlies the development of striatal compartments. Brain Res 401:155-161.

Wakabayashi Y, Watanabe H, Inoue J, Takeda N, Sakata J, Mishima Y, Hitomi J, Yamamoto T, Utsuyama M, Niwa O, Aizawa S, Kominami R (2003) Bcll1b is required for differentiation and survival of $\alpha \beta$ T lymphocytes. Nat Immunol 4:533-539.

Watakabe A, Ohsawa S, Hashikawa T, Yamamori T (2006) Binding and complementary expression patterns of semaphorin $3 \mathrm{E}$ and plexin $\mathrm{D} 1$ in the mature neocortices of mice and monkeys. J Comp Neurol 499:258-273

Wichterle H, Turnbull DH, Nery S, Fishell G, Alvarez-Buylla A (2001) In utero fate mapping reveals distinct migratory pathways and fates of neurons born in the mammalian basal forebrain. Development 128:3759-3771.

Yun K, Potter S, Rubenstein JL (2001) Gsh2 and Pax6 play complementary roles in dorsoventral patterning of the mammalian telencephalon. Development 128:193-205. 